people to accept any other kind of money. For other countries there may be a prolonged period during which a struggle will be made to restore equilibrium between taxes and outgo in the public budgets, and to fund the public floating debts, including the debts of the states to the banks of issue, with a consequent reduction in the volume of bank notes outstanding, and with the ultimate resumption of specie payments held in view.

One must protest, however, against Professor Cassel's statement that "the restoration of the old gold parities is, as everybody knows, quite out of the question." Some countries may be unable to reëstablish their old gold standards, but many of the countries of Europe will be able to do so, and most will at least be justified in making the attempt to do so. In any case it can be confidently asserted that no stability in international exchange rates will be possible until the currencies of the world are again at a fixed ratio with gold, and that the only way in which a currency can be kept at a fixed ratio with gold is to redeem it directly or indirectly in gold on demand. I say "directly or indirectly" wishing to allow room in the generalization for such cases as "gold exchange standard," under which the gold reserve is held in a foreign country, and under which the currency of a country is redeemed in gold bills drawn on that foreign country, rather than in actual coin. This constitutes, however, merely a modification of the gold standard proper, and can work effectively only if actual gold can be secured at the end of the process. We must especially guard ourselves against the notion that any scheme for the regulation of the quantity of an irredeemable paper money can lead to stability, either in the internal or in the external value of that paper.

In summary: finding much that is interesting and important in Professor Cassel's paper, I limit my discussion to the points of dissent. I think that he minimizes the really important factors affecting the exchange rates, such as the trade balances, the growing distrust of irredeemable paper money, and the like, and that he is dealing with a myth when he speaks of "purchasing power parities" as governing exchange rates between countries, both of which have inconvertible paper money. The only parity that can have any meaning in international exchange rates is a gold (or silver) parity, and when gold is abandoned, "parity" ceases to mean anything. Stability in international exchange rates depends on the restoration of the gold standard.

\title{
DISCUSSION OF PROFESSOR CASSEL'S ARTICLE
}

\section{By Lord D'Abernon \\ Surrey, England}

It is a keen intellectual pleasure to read Professor Cassel's brilliant statement on "The World's Monetary Problem" and to contrast it with the puerile inanities which form the basis of most that is written and spoken on the subject.

To show how widely Professor Cassel's views differ from those generally held, it may be well to place in close 
juxtaposition and in clear relief the popular view and those set forth in the article under review.

The popular view is that the exchanges will right themselves when trade resumes its normal course.

Professor Cassel holds that this return to the old basis is quite out of the question.

The rise of prices is popularly attributed to high cost of transport, to diminished output of labor, etc.

Professor Cassel holds that there can be no independent cause of a rise in the upward movement of prices other than a decrease in the total mass of commodities and an increased supply of money-the latter cause being in the present case incomparably the most important.

It is generally thought that an unfavorable exchange favors the export trade of a given country and impedes the import trade.

Professor Cassel holds that once exchange is stabilized, it is of no importance whether the level is high or low.

People generally explain a low exchange as the result of an adverse balance of trade.

Professor Cassel points out that this explanation is quite inadequate to explain considerable and non-temporary fluctuations. These can be explained only by inflation which has brought down the internal value of the monetary unit of the country.

The popular expectation is that the old exchange level can be restored by increased exports.

Professor Cassel holds that this is only possible where the low exchange has been caused exclusively by wartime prohibitions of export. Where the cause is an internal depreciation of the monetary unit through an excessive supply of currency, a reduc. tion of inflation is the only remedy.

The popular view is that a general rise of prices can be prevented by legislation against profiteering and the enactment of maximum prices.

Professor Cassel says that result is unattainable so long as the government is incessantly flooding the country with fresh money, and the bank rate is kept too low.

The popular view is that heaping up masses of gold in a central bank will improve the monetary standard.

This the Professor regards as an illusion, the value of the money of any country being solely determined by the scantiness of the supply of means of payment relative to the demand for means of payment. Unless the national currency is on a par with gold, gold in the vaults is not much more than an empty show.

It is generally believed that a higher value would be attained by the national currency (leading to improved exchanges and a reduced cost of living) if the government of the country can reëstablish its credit.

This view the Professor holds to be false, the sole reason of the depreciated currency being superabundance.

The general view is that prices will by and by come down to their old level by themselves. This view is held by the Professor to be quite groundless in the absenc of definite measures of monetary policy.

The above enumeration by no means exhausts the list of articles of popular currency belief which Professor Cassel holds to be totally erroneous and misleading. 
The question is, are these statements merely scintillations of academic para' $x$ written as intellectual amusement, or are they the expression of a complete theory of currency and prices, fundamentally different from the vague beliefs on which the slipshod monetary policy of nearly all the governments of the world is based? The two conceptions of the problem are so divergent that no compromise or half-way house is possible between them.

If the Professor is right, the monetary policy which is now being followed in most countries in the world is radically wrong, and will lead, unless modified, to an aggravation of the discontent, unrest and financial disturbance which now prevail.

If the Professor is wrong, it must be shown where the fallacy lies, and recorded facts must be explained and reconciled on some other general hypothesis.

Personally, I agree with Professor Cassel in nearly all his main conclusions, and $I$ regard his paper as at once the boldest and the most clear-cut statement which has yet been made on the problem.

This is not the moment to discuss some minor differences, when general identity of view is proclaimed.

The facts recorded in the Monthly Bulletin of the Supreme Economic Council, and those presented still more strikingly in the White Paper (Command Paper 434) are not explainable on any other hypothesis.
Unless a general theory similar to that stated in the present paper is adopted, what explanation is there of the admitted fact that prices in each country have risen in direct proportion to the over-supply of currency, and that foreign exchange in each country has fallen in nearly similar proportion? Is any such result conceivable if superabundance of currency was either a non-existent cause or a minor cause? Do not the facts and figures point directly to the conclusion that currency is the dominant factor?

Great importance is attached in some quarters to the influence of excessive imports and inadequate exports, but in Russia where the disturbances caused by inflation are seen in their most extreme form, and where prices are higher and exchange is lower than anywhere else, there has certainly been no excessive importation of foreign goods; similarly with Germany and Austria. Does anyone contend that the fall of the mark to one-tenth its par value or lower has been caused by an excess of importation from abroad?

The conclusion of the whole matter is that a faulty currency policy during the war and still more since the war has been the main cause of high prices and low exchange, and of all the resulting unrest and disturbance. Until a wiser currency policy is adopted by the great nations of the world, there is no chance of permanent improvement. 